\title{
Interfacial phase formation of Al-Cu bimetal by solid-liquid casting method
}

\author{
Ying Fu',2, *Yu-bo Zhang', Jin-chuan Jie', Kateryna Svynarenko', Chang-hai Liang ${ }^{3}$, and Ting-ju Li ${ }^{1}$ \\ 1. School of Materials Science and Engineering, Dalian University of Technology, Dalian 116024, Liaoning, China; \\ 2. Research Institute of Mechatronics \& Automation, Bohai University, Jinzhou 121003, Liaoning, China; \\ 3. School of Chemical Engineering, Dalian University of Technology, Dalian 116024, Liaoning, China
}

\begin{abstract}
The solid-liquid method was used to prepare the continuous casting of copper cladding aluminium by liquid aluminum alloy and solid copper, and the interfacial phase formation of $\mathrm{Al}-\mathrm{Cu}$ bimetal at different pouring temperatures $\left(700,750,800^{\circ} \mathrm{C}\right)$ was investigated by means of metallograph, scanning electron microscopy (SEM) and energy dispersive spectrometry (EDS) methods. The results showed that the pouring temperature of aluminum melt had an important influence on the element diffusion of $\mathrm{Cu}$ from the solid $\mathrm{Cu}$ to $\mathrm{Al}$ alloy melt and the reactions between $\mathrm{Al}$ and $\mathrm{Cu}$, as well as the morphology of the $\mathrm{Al}-\mathrm{Cu}$ interface. When the pouring temperature was $800{ }^{\circ} \mathrm{C}$, there were abundant $\mathrm{Al}-\mathrm{Cu}$ intermetallic compounds (IMCs) near the interface. However, a lower pouring temperature $\left(700{ }^{\circ} \mathrm{C}\right)$ resulted in the formation of cavities which was detrimental to the bonding and mechanical properties. Under the conditions in this study, the good metallurgical bonding of Al-Cu was achieved at a pouring temperature of $750^{\circ} \mathrm{C}$.
\end{abstract}

Key words: Al-Cu clad materials; interface; solid-liquid method; microstructure
CLC numbers: TG146.21
Document code: A
Article ID: 1672-6421(2017)03-194-05

$\mathrm{B}$ metal clad refers to a new type of material, which s prepared by combination of two different alloys with different physical, chemical, or mechanical properties, in order to achieve better properties in comparison to a single metal material ${ }^{[1-2]}$. Hence, such materials have a far reaching potential in manufacturing applications. For example, the $\mathrm{Al}-\mathrm{Cu}$ bimetal wire, i.e. the $\mathrm{Cu}$ clad $\mathrm{Al}$ (CCA) wire, could offer a $50 \%$ reduction in weight and $30 \%-40 \%$ reduction in cost for the equivalent conductivity, compared with monolithic copper alloys ${ }^{[3]}$. For this reason, the CCA wire is a candidate to replace the conventional $\mathrm{Cu}$ alloys in cables, yoke coils, air-cooling fins and bus-bar conductor joints.

Many manufacturing methods, such as explosive welding ${ }^{[4]}$, roll bonding ${ }^{[5-6]}$, diffusion bonding ${ }^{[7]}$, and casting ${ }^{[8-11]}$, were used to produce clad metals. Among those, the casting technique is considered an optimal one due to its high efficiency and low cost ${ }^{[12-16]}$. In recent years, the casting method has been widely applied to produce different kinds of bimetal composites. In this

\footnotetext{
* Yu-bo Zhang

Male, born in 1985, lecturer. His research interests mainly focus on the fabrication of metal matrix composite and the electromagnetic casting of nonferrous metals.

E-mail: ybzhang@dlut.edu.cn
}

Received: 2016-04-21; Accepted: 2016-12-26 method, two different metal melt are poured into the mold successively, then the clad ingot is pulled out from the other side, obtaining a good metallurgical bonding during the continuous process. The key point of this fabrication technology is the formation mechanism of the clad materials' interface. In the case of CCA material, the horizontal continuous casting is a widely used method for the preparation of hollow, round and square CCA billets. During the conventional process, the copper is firstly poured into the outer mold and shaped because of its higher melting point, and then the aluminum melt is poured and combined with the solidified clad-copper. Adequate remelting and sufficient element diffusion process lead to a good metallurgical bonding, whereas, the excessive or insufficient combination results in defects near the interface and deterioration of the performance.

We prepared the CCA round billet by the horizontal continuous casting method. It was found that the interfacial reaction and bonding between aluminum and copper could determine the success or failure of the whole experiment. Parameters such as pouring temperature, casting speed, and cooling water consumption, which affect the interface reaction, play important roles in the continuous casting process. The pouring temperature of aluminum is considered significant. In this study, a mold casting with solid copper and liquid aluminum alloy was 
carried out to study the reaction and the interfacial phase formation of $\mathrm{Al}-\mathrm{Cu}$ bimetal, and to optimize parameters for the continuous process.

\section{Experimental method}

The materials used in this experiment were Al-7\%Si alloy and pure copper. The surface of the copper bar was first ground by fine abrasive paper in order to degrease and remove the oxide film. The schematic diagram of the experimental setup is shown in Fig. 1. The $\mathrm{Cu}$ bar (preheated to $250{ }^{\circ} \mathrm{C}$ ) was installed in the mold and then the aluminum melt was poured in. The pouring temperature was $700{ }^{\circ} \mathrm{C}, 750{ }^{\circ} \mathrm{C}$ and $800{ }^{\circ} \mathrm{C}$, respectively. After obtaining the clad ingot, it was cut transversely, and then ground, polished, and etched by $5 \% \mathrm{NaOH}$ solution for testing. The microstructure at the interface was observed using optical microscopy, SEM and electron probe X-ray microanalyses. The Vickers hardness profile was measured along the interface layer, and the hardness tests were performed under an indentation load of $100 \mathrm{~g}$ for $5 \mathrm{~s}$.

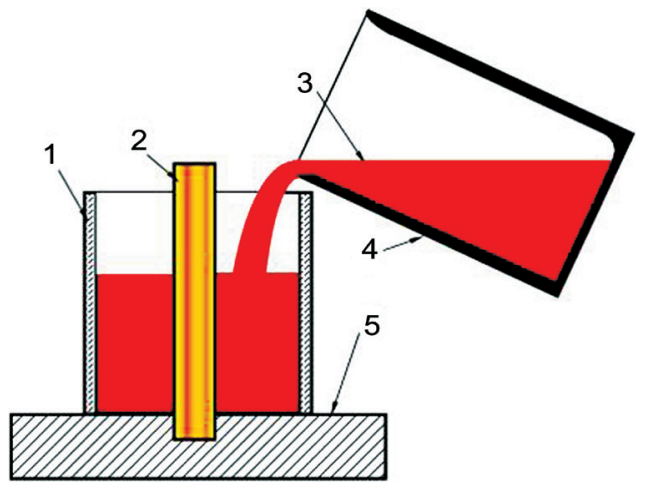

(1) mold; (2) pure Cu; (3) Al-7\%Si melt; (4) graphite crucible; (5) thermal insulating plate

Fig. 1: Schematic diagram of experiment

\section{Results}

\subsection{Macrostructure and microstructure}

Figures 2 and 3 show the macro- and microstructures of Al$\mathrm{Cu}$ clad ingots. When the pouring temperature is $800{ }^{\circ} \mathrm{C}$, the shape of the copper bar is distorted significantly due to remelting by the high temperature $\mathrm{Al}$ melt (Fig. 2a), and a lot of $\mathrm{Al}-\mathrm{Cu}$ intermetallic compounds (IMCs) can be seen near the interface (Fig. 3a). When the pouring temperature decreases to $750{ }^{\circ} \mathrm{C}$, a good bonding is obtained (Fig. 2b), and no evidence of $\mathrm{Cu}$ overmelting or casting defects near the interface are observed in the macrostructure. In addition, there are scarcely any IMCs in the diffusion zone (Fig. 3b), and the interface between Al-7Si and pure $\mathrm{Cu}$ is quite clear. In the case of pouring temperature $700{ }^{\circ} \mathrm{C}$, obvious cracks and cavities due to insufficient reaction are found near the interface (Figs. 2c and 3c), which are detrimental to the bonding of the two alloys. The results also show that the width of the reaction layer of the $\mathrm{Al}-\mathrm{Cu}$ is narrowed with the decrease of pouring temperature.

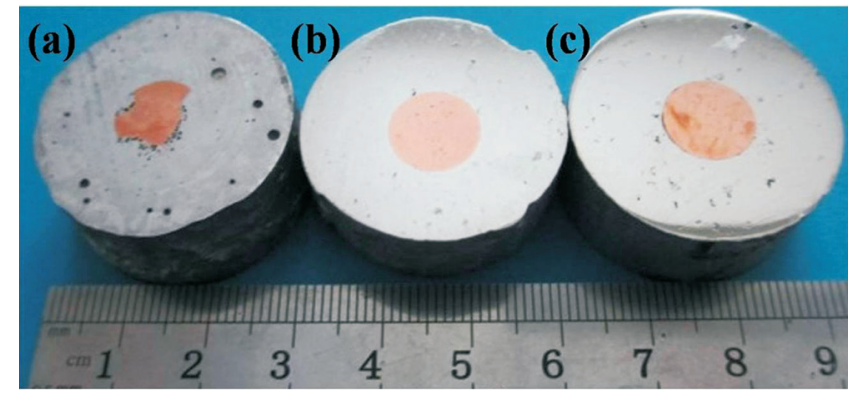

Fig. 2: Macrostructures of clad ingots with different pouring temperatures: (a) $800{ }^{\circ} \mathrm{C}$, (b) $750{ }^{\circ} \mathrm{C}$, (c) $700^{\circ} \mathrm{C}$
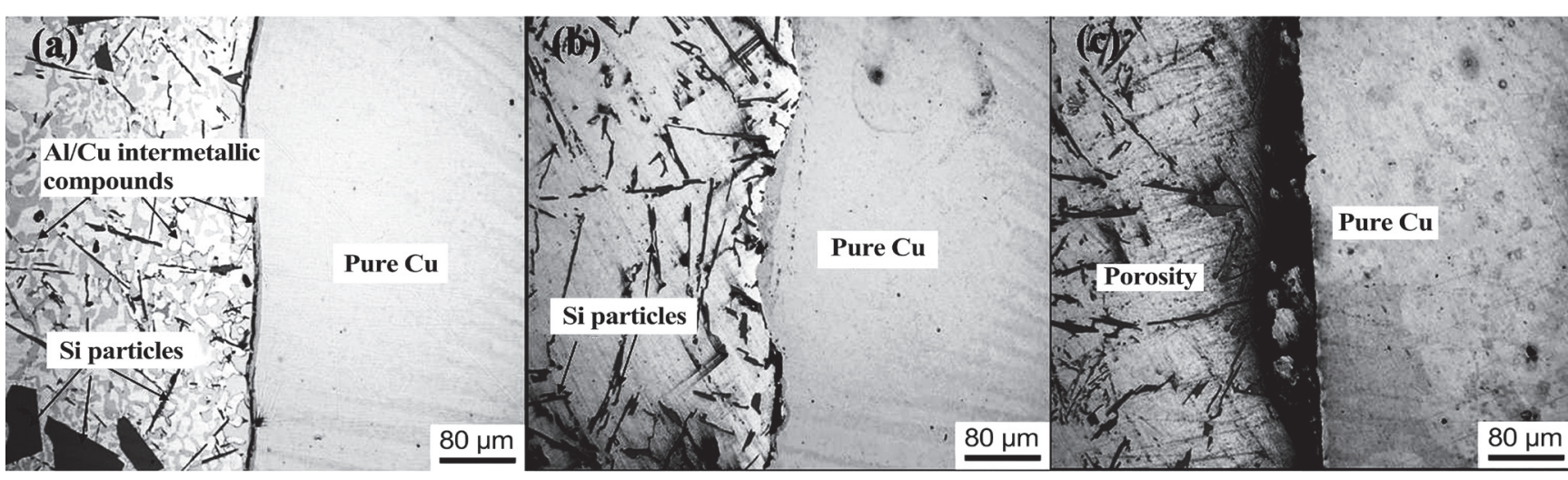

Fig. 3: Microstructures of interface region in clad ingots with different pouring temperatures: (a) $800{ }^{\circ} \mathrm{C}$, (b) $750^{\circ} \mathrm{C}$, (c) $700{ }^{\circ} \mathrm{C}$

In order to study the reaction between liquid aluminum and solid copper, further analysis was carried out by means of SEM and EDS. Figure 4a shows the SEM images taken from the $\mathrm{Al}-\mathrm{Cu}$ interface with the $\mathrm{Al}$ pouring temperature of $800{ }^{\circ} \mathrm{C}$. Several areas of diverse microstructure with different shapes of
IMCs can be observed near the interface. Those are marked and magnified in Fig. 4b-d. Figure 4b shows the interfacial region of Al-Cu clad material, which consists of 5 layers: pure $\mathrm{Cu}, \delta$ phase $\left(\mathrm{Cu}_{3} \mathrm{Al}_{2}\right), \mathrm{CuAl}, \mathrm{CuAl}_{2}$, and pure $\mathrm{Al}$ matrix in turn from the outside to the inside part of the ingot. The results of phase 


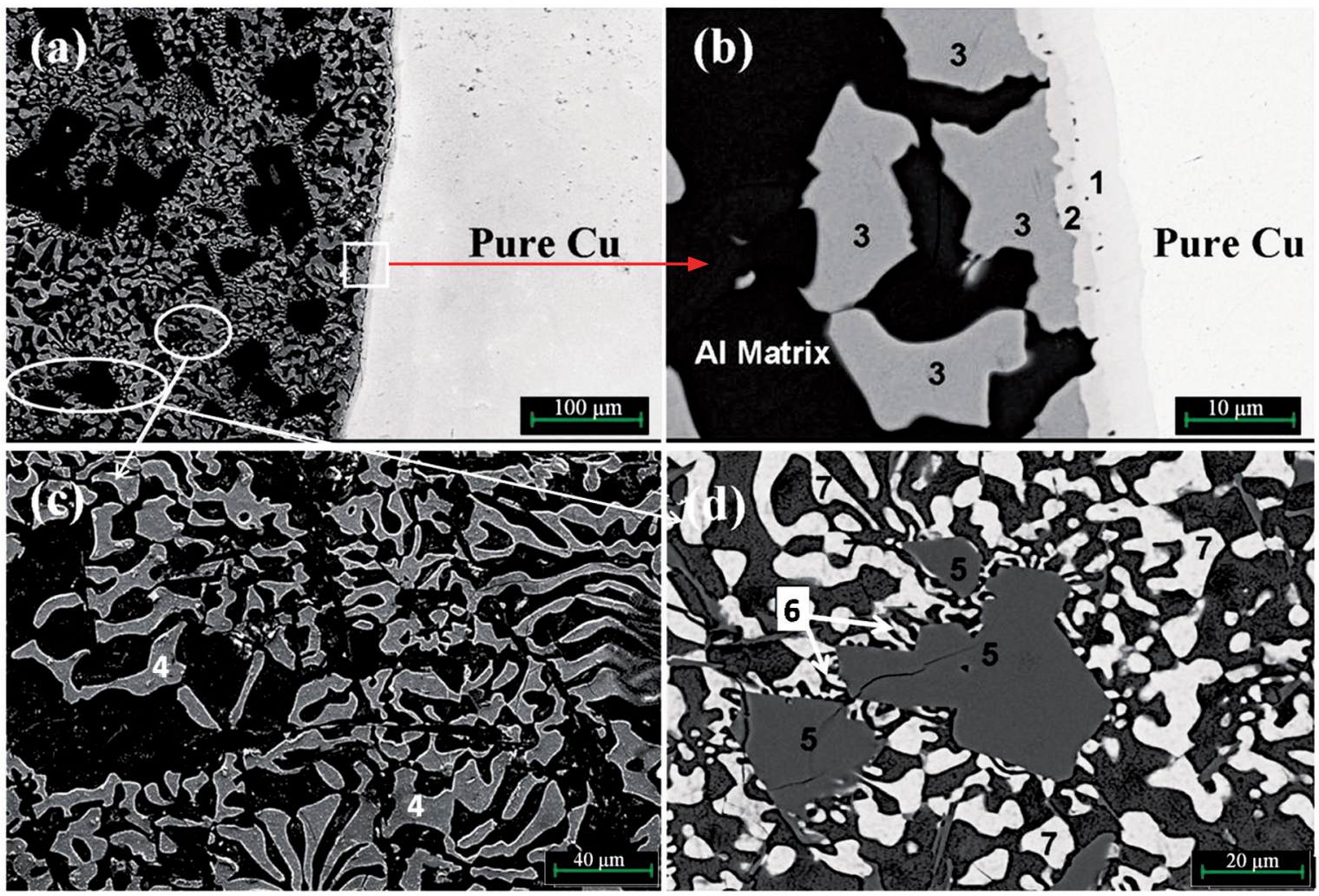

Fig. 4: SEM micrograph of Al-Cu interface when pouring at $800^{\circ} \mathrm{C}$

Table 1: Elemental analysis results of Al-Cu interfaces by EDS

\begin{tabular}{|c|c|c|c|c|}
\hline \multirow{2}{*}{ Position } & \multicolumn{3}{|c|}{ Element (at.\%) } & \multirow{2}{*}{ Suggested IMCs } \\
\hline & Al & $\mathrm{Cu}$ & Si & \\
\hline 1 & 36.140 & 63.860 & - & $\delta$ \\
\hline 2 & 49.491 & 50.509 & - & CuAl \\
\hline 3 & 65.769 & 34.231 & - & $\mathrm{CuA}_{12}$ \\
\hline 4 & 63.68 & 35.35 & 0.98 & $\mathrm{CuAl}_{2}$ \\
\hline 5 & - & - & 100 & $\mathrm{Si}$ \\
\hline 6 & 71.36 & 27.73 & 0.92 & $\mathrm{CuAl}_{2}$ \\
\hline 7 & 64.66 & 34.13 & 1.22 & $\mathrm{CuAl}_{2}$ \\
\hline
\end{tabular}

composition are based on the EDS analysis, listed in Table 1. It is noted that the content of $\mathrm{Cu}$ is gradually reduced from the $\mathrm{Cu}$ side to the $\mathrm{Al}$ side. Because of the overreaction of $\mathrm{Al}-\mathrm{Cu}$ at high pouring temperature, $\mathrm{Cu}$ element diffuses deeply through the $\mathrm{Al}$ matrix, and a large amount of $\mathrm{CuAl}_{2}$ phase generates in the $\mathrm{Al}$ matrix (Fig. 4c). The Al-Cu reaction also has an influence on the $\mathrm{Al}-\mathrm{Si}$ eutectic reaction: due to the consumption of $\mathrm{Al}$ element during the Al-Cu reaction, part of Si precipitates in the form of primary Si (Fig. 4d).

\subsection{Vickers hardness}

Figure 5 shows the Vickers hardness profile measured perpendicular to the $\mathrm{Al}-\mathrm{Cu}$ interface. When the pouring

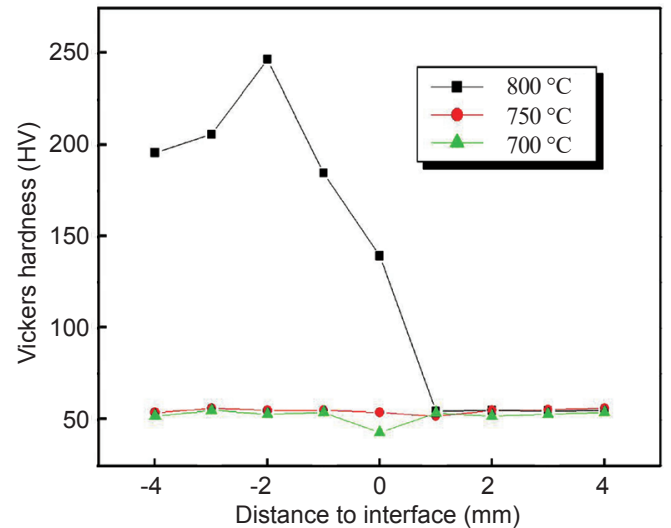

Fig. 5: Vickers hardness across interface of Al-Cu ingots 
temperature of aluminum melt is $800{ }^{\circ} \mathrm{C}$, the micro-hardness values are much higher at the $\mathrm{Al}$ side and get an obvious decrease at the $\mathrm{Cu}$ side. As mentioned above, numerous $\mathrm{Al}$ $\mathrm{Cu}$ IMCs are formed in the $\mathrm{Al}$ matrix at a higher pouring temperature, and such hard phases make a great contribution to the hardness of the alloy. At 750 and $700{ }^{\circ} \mathrm{C}$ pouring temperatures, the variation trend of micro-hardness is fitted reasonably well to a horizontal line, since the $\mathrm{Al}-\mathrm{Si}$ and $\mathrm{Cu}$ have almost equal performance of hardness.

\section{Discussion}

It is clear that the reasonable pouring temperature of $\mathrm{Al}-\mathrm{Cu}$ clad ingot by this solid-liquid bonding method is $750^{\circ} \mathrm{C}$, at which a good bonding between $\mathrm{Al}-\mathrm{Cu}$ is obtained without overreaction or cavities. Hence, $750{ }^{\circ} \mathrm{C}$ is considered the optimal pouring temperature of $\mathrm{Al}$ melt in this study.

In the case of $800{ }^{\circ} \mathrm{C}$ pouring temperature, even though it is much lower than the melting point of pure copper $\left(1,083{ }^{\circ} \mathrm{C}\right)$, the copper bar is still remelted and extremely misshapen. The schematic view of the probable process-formed $\mathrm{Al}-\mathrm{Cu}$ diffusion zone is shown in Fig. 6. When the $\mathrm{Al}$ melt of $800{ }^{\circ} \mathrm{C}$ contacts with the solid $\mathrm{Cu}$, the thermal stress on the micro-zone of the copper surface is stronger than its yield strength, resulting in the plastic deformation and creeping of copper. In this case, the $\mathrm{Cu}$ surface starts to be melted and reacts with liquid aluminum, forming the Al-Cu IMCs. Since there is a concentration gradient of $\mathrm{Cu}$ element from the $\mathrm{Cu}$ side to $\mathrm{Al}$ side, due to the gradual dissolution of $\mathrm{Cu}$ bar, the $\mathrm{Al}-\mathrm{Cu}$ surface is formed with 5 layers of pure $\mathrm{Cu}, \delta$ phase $\left(\mathrm{Cu}_{3} \mathrm{Al}_{2}\right), \mathrm{CuAl}, \mathrm{CuAl}_{2}$, and pure $\mathrm{Al}$ matrix in turn. The natural convection in the Al melt may lead to detachment of these IMCs, therefore, a large amount of $\mathrm{Al}-\mathrm{Cu}$ IMCs (mostly $\mathrm{CuAl}_{2}$ phase) are observed in the $\mathrm{Al}$ matrix.

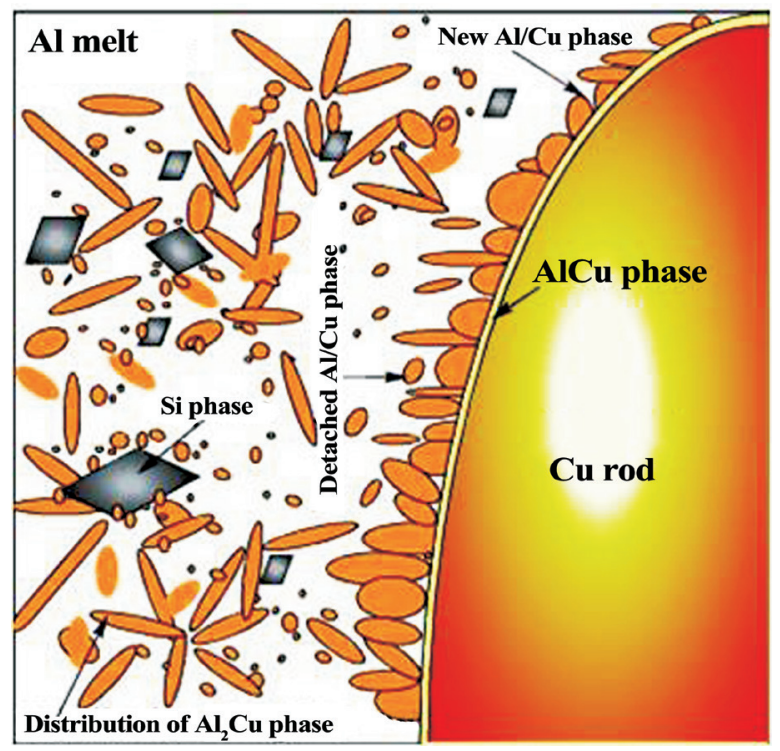

Fig. 6: Schematic drawing of formation mechanism of Cu-Al interface
When the liquid aluminum contacts with solid copper, there will be an inter-diffusion between copper and aluminum. At the initial stage, it needs an incubation period to form IMCs at the interface, which is defined as $t_{0}$, and can be expressed as follows:

$$
t_{0}=k \exp \left[\frac{A+E}{R T}\right]
$$

where, $k$ is dissolving constant of reaction phase, $A$ is effective activation energy during this process, $E$ is atomic activation energy of dissolving element, $R$ is gas constant, $T$ is absolute temperature. From this equation, it can be considered that the higher reaction temperature will lead to the shorter incubation time of IMCs formation. The growth of an IMC phase layer may be entirely controlled by diffusion, reaction rate, or the two processes simultaneously.

When the reaction between $\mathrm{Al}$ and $\mathrm{Cu}$ occurs, $\mathrm{CuAl}_{2}$ phase forms firstly, which is considered as the easiest formation of Al$\mathrm{Cu}$ product, and is detrimental to the interfacial bonding due to its brittleness. However, $\delta$ phase $\left(\mathrm{Cu}_{3} \mathrm{Al}_{2}\right)$ and $\mathrm{CuAl}$ are also observed near the interface in this study, implying that other reactions occur during the solidification, which result in the formation of $\mathrm{Cu}_{3} \mathrm{Al}_{2}$ and $\mathrm{CuAl}$.

Assuming that $\mathrm{Cu}_{3} \mathrm{Al}_{2}$ phase is formed by the interaction of $\mathrm{Cu}$ atom and $\mathrm{CuAl}_{2}$ via the following reaction:

$$
2 \mathrm{Cu}+\mathrm{CuAl}_{2} \rightarrow \mathrm{Cu}_{3} \mathrm{Al}_{2}
$$

the standard molar Gibbs free energy is given:

$\Delta_{r} G_{m}{ }^{0}=\Delta_{f} G_{m}{ }^{0}\left(\mathrm{Cu}_{3} \mathrm{Al}_{2}, s\right)-\Delta_{f} G_{m}{ }^{0}\left(\mathrm{CuAl}_{2}, s\right)-2 \Delta_{f} G_{m}{ }^{0}(\mathrm{Cu}, s)$

For pure copper, the standard Gibbs free energy of formation $\Delta_{f} G^{0}=0$, the standard molar enthalpy of formation $\Delta H_{298}^{0}=0$, the standard molar entropy $S_{298}^{0}=33.35\left(\mathrm{~J} \cdot \mathrm{mol}^{-1} \cdot \mathrm{K}^{-1}\right)$, and isobaric heat capacity $C_{p}=22.64+6.28 \times 10^{-3} T\left(\mathrm{~J} \cdot \mathrm{mol}^{-1} \cdot \mathrm{K}^{-1}\right)$.

The change of standard molar Gibbs energy is given:

$$
\begin{aligned}
& \Delta G=\Delta H-\Delta(T S) \\
& \Delta H=\int_{298}^{T} C_{p} d T=\int_{298}^{T}\left(22.64+6.28 \times 10^{-3} T\right) d T \\
& =3.14 \times 10^{-3} T^{2}+22.64 T-7025.56 \\
& \Delta(T S)=T_{2} S_{2}-T_{1} S_{1}=T \times\left(S_{298}^{0}+\int_{298}^{T} \frac{C_{p}}{T} d T\right)-298 \times S_{298}^{0} \\
& =6.28 \times 10^{-3} T^{2}+22.64 T \ln \left(\frac{T}{298}\right)+33.35 T-9938.3
\end{aligned}
$$

Therefore,

$\Delta_{f} G_{m}^{0}(\mathrm{Cu}, s)=-3.14 \times 10^{-3} T^{2}+22.64 T \ln \left(\frac{T}{298}\right)-10.71 T+2912.74$

Under the conditions of standard pressure and temperature, the standard molar Gibbs free energy of the Al-Cu IMCs can be calculated as follows ${ }^{[17]}$ :

$$
\begin{gathered}
\Delta G_{m}^{0}\left(\mathrm{Cu}_{3} \mathrm{Al}_{2}, s\right)=-128440+36.9 T \\
\Delta G_{m}^{0}\left(\mathrm{CuAl}_{2}, s\right)=-77100+22.3 T
\end{gathered}
$$




$$
\Delta G_{m}^{0}(\mathrm{CuAl}, s)=-51380+14.8 T
$$

When $T$ is $1,073 \mathrm{~K}\left(800{ }^{\circ} \mathrm{C}\right), \Delta_{r} G_{m}{ }^{0}<0$, indicating that the reaction (2) can occur spontaneously. The results suggest that the aluminum melt contacts with the copper bar, forming $\mathrm{CuAl}_{2}$ phase in the $\mathrm{Al}$ matrix. Then $\mathrm{Cu}_{3} \mathrm{Al}_{2}$ phase precipitates by the reaction between $\mathrm{Cu}$ and $\mathrm{CuAl}_{2}$. Meanwhile, the reaction $\mathrm{CuAl}_{2}$ $+\mathrm{Cu}_{3} \mathrm{Al}_{2} \rightarrow 4 \mathrm{CuAl}$ also occurs spontaneously (the Gibbs free energy can be calculated in the same way as described above). This explains the presence of $\delta-\mathrm{Cu}_{3} \mathrm{Al}_{2}$ phase and $\mathrm{CuAl}$ layer in the transition region between $\mathrm{Cu}$ and $\mathrm{Al}$ matrix.

Meanwhile, the pouring temperature can also influence the $\mathrm{Al}-\mathrm{Cu}$ reaction by the element diffusion of $\mathrm{Cu}$ atoms. At the $800{ }^{\circ} \mathrm{C}$ pouring temperature, the diffusion rate of $\mathrm{Cu}$ from the solid to the $\mathrm{Al}$ melt is larger than that at lower temperatures (700 and $750^{\circ} \mathrm{C}$ ), resulting in an increased amount of $\mathrm{Cu}$ atoms in the $\mathrm{Al}$ melt. This will promote the reaction between $\mathrm{Cu}$ and $\mathrm{Cu}-$ $\mathrm{Al}$ IMCs, as well as the formations of $\mathrm{CuAl}_{2}, \mathrm{Cu}_{3} \mathrm{Al}_{2}$ and $\mathrm{CuAl}$. In this case, abundant $\mathrm{Al}-\mathrm{Cu}$ IMCs such as $\mathrm{CuAl}_{2}, \mathrm{Cu}_{3} \mathrm{Al}_{2}$ and $\mathrm{CuAl}$ can be found near the interface at the condition of $800^{\circ} \mathrm{C}$. In the case of pouring temperature $700{ }^{\circ} \mathrm{C}$, the element diffusion of $\mathrm{Cu}$ and the reactions between $\mathrm{Al}-\mathrm{Cu}$ IMCs are not sufficient for the formation of stable interfacial bonding, with a result of cavities and other casting defects. In contrast, the good bonding was achieved at the reasonable pouring temperature of $750{ }^{\circ} \mathrm{C}$, with a good interface of metallurgical bonding and no defects by appropriate element diffusion of $\mathrm{Cu}$ and reaction between $\mathrm{Al}$ and $\mathrm{Cu}$.

\section{Conclusion}

The solid-liquid bonding method was carried out to investigate the phase formation of liquid aluminum alloy and solid copper. The results indicate that the pouring temperature of $\mathrm{Al}$ melt has a big influence on the interfacial microstructure and phase formation, by promoting the $\mathrm{Cu}$ diffusion from the solid to the $\mathrm{Al}$ melt and the reaction between $\mathrm{Cu}$ and $\mathrm{Al}$. Under the conditions in this study, the reasonable $\mathrm{Al}$ pouring temperature is $750{ }^{\circ} \mathrm{C}$, with a good bonding between $\mathrm{Al}$ and $\mathrm{Cu}$. As a contrast, excess $\mathrm{Al}-\mathrm{Cu} \mathrm{IMC}$ phases form near the interface at $800{ }^{\circ} \mathrm{C}$, and cavities as well as other defects can be found at the lower pouring temperature of $700{ }^{\circ} \mathrm{C}$.

\section{References}

[1] Miller W S, Zuang L, Bottema J. Recent development in aluminum alloys for the automotive industry. Materials Sciences and Engineering A, 2000, 280(1): 37-49.
[2] Xue Zhiyong, Liang He, Yu Wanhua, et al. Orthogonal tests of copper-clad aluminum bimetal continuous casting by nitrogen pressure core-illing. China Foundry, 2013, 10(6): 385-390.

[3] Rhee $\mathrm{K} Y$, Han $\mathrm{W} Y$, Park H J, et al. Fabrication of aluminum/ copper clad composite using hot hydrostatic extrusion process and its material characteristics. Materials Sciences and Engineering A, 2004, 384(1-2): 70-76.

[4] Kacar R, Acarer M. An investigation on the explosive cladding of 316L stainless steel-din-P355GH steel. Journal of Materials Processing Technology, 2004, 152(1): 91-96.

[5] Eizadjou M, Manesh H D, Janghorban K. Investigation of roll bonding between aluminum alloy strips. Materials \& Design, 2008, 29(4): 909-13.

[6] Li Xiaobing, Zu Guoyin, Wang Ping. Microstructural development and its effects on mechanical properties of Al/ Cu laminated composite. Transactions of Nonferrous Metals Society of China, 2015, 25(1): 36-45.

[7] Wang Deqing, Shi Ziyuan, Qi Ruobin. Cladding of stainless steel on aluminum and carbon steel by interlayer diffusion bonding. Scripta Materialia, 2007, 56(5): 369-72.

[8] Su Yajun, Liu Xinhua, Huang Haiyou, et al. Interfacial microstructure and bonding strength of copper cladding aluminum rods fabricated by horizontal core-filling continuous casting. Metallurgical and Materials Transactions, 2011, 42A: 4088-4099.

[9] Jiang Huixue, Zhang Haitao, Qin Ke, et al. Direct-chill semicontinuous casting process of three-layer composite ingot of 4045/3004/4045 aluminum alloys. Transactions of Nonferrous Metals Society of China, 2011, 21(8): 1692-1697.

[10] Rong S, Zhou H, ZhuY, et al. Study on liquid-liquid bimetal composite casting hammers. China Foundry, 2014, 11(5): 412417.

[11] Xiao X, Ye S, Yin W, et al. High Cr white cast iron/carbon steel bimetal liner by lost foam casting with liquid-liquid composite process. China Foundry, 2012, 9(2):136-142.

[12] Li Na, Guo Shouren, Lu Dezhong, et al. Technique of aluminum alloy composite by inversion casting. Journal of Materials Sciences and Technology, 2002, 18(2): 187-188.

[13] Takeuchi E, Zeze M, Tanaka H, et al. Novel continuous casting process for clad steel slabs with level DC magnetic field. Ironmaking and Steelmaking, 1997, 24(3): 257-263.

[14] Fu Ying, Jie Jinchuan, Wu Li, et al. Microstructure and mechanical properties of Al-Mn and Al-Si alloy clad ingot by continuous casting. Materials Science and Engineering A, 2013, 561: 239-244.

[15] Bendyk J C. Novelis FusionTM process: Breakthrough in the simultaneous DC casting of multiple aluminum alloy layers for rolling ingot. Light Metal Age, 2006(8): 48-50.

[16] Zhang Weiwen, Zou Ganfeng, Deng Changning, et al. Investigation of production of gradient material by continuous casting. Acta Metallurgica Sinica, 1998, 34(6): 610-614.

[17] Wang Da. Study on the bonding mechanism and interface reaction of Cu/Al laminated composite. Master thesis, Jiangxi University of Technology, 2011. (In Chinese) 